\title{
Sciendo
}

RURAL SUSTAINABILITY RESEARCH 44(339), 2020

ISSN - 2256-0939

(c) Latvia University of Life Sciences and Technologies, all rights reserved

http://www.llu.lv/en/

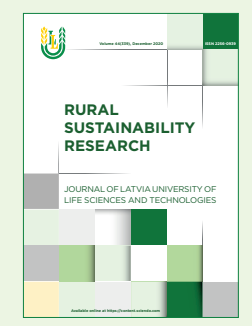

Received: 21 September 2020

Revised: 19 October 2020

Accepted: 21 October 2020

\section{The Evaluation of Fatty Acid Profile in the Diet of Patients in Psycho- neurological Hospitals}

\author{
Ilze Beitane, Alla Marisheva \\ Latvia University of Life Sciences and Technologies, 22 Rigas Street, Jelgava, Latvia
}

\begin{abstract}
There is a strong correlation between diet and mental health, and malnutrition can contribute to the development of various psycho-neurological diseases. Fatty acid profile plays an important role in the treatment of psycho-neurological diseases; therefore, the aim of the current study was to evaluate fatty acid profile in the diet of patients in three Latvian psycho-neurological hospitals. Latvian psycho-neurological hospitals submitted a detailed one-week menu. The information in the menus was processed using the Fineli program. Each menu identified the composition of fatty acids.

The average fat concentration in different hospital menus ranged from $74.8 \mathrm{~g}$ to $96.1 \mathrm{~g}$ per day, where the concentration of saturated fatty acids ranged from $37.5 \mathrm{~g}$ to $47.7 \mathrm{~g}$ per day and the unsaturated fat concentration ranged from $35.9 \mathrm{~g}$ to $47 \mathrm{~g}$ per day. The n-3 PUFA content was consistent with the recommendations of a healthy individual, but it did not meet the needs of patients in a psycho-neurological hospital. The total eicosapentaenoic acid and docosahexaenoic acid concentration in the hospital menus ranged from 0.03 to 0.13 $\mathrm{g}$, which was significantly lower than recommended, whereas LA and ALA concentration in hospital menus is close to optimal. The trans-fatty acids concentration in hospital menus did not exceed $2.5 \mathrm{~g}$ per day, with the exception of one day in hospital No. 2.

The impact of diet on the treatment of psycho-neurological diseases in Latvian psycho-neurological hospitals has not been sufficiently assessed.
\end{abstract}

Key words: saturated and unsaturated fatty acids, trans-fatty acids, mental health.

\section{Introduction}

Nutrition plays an important role in ensuring human health, as nutrients contribute to the various functions of the body. Many nutrients ensure the normal functioning of the brain (Kaplan et al., 2015), which is a prerequisite for mental health. In addition, the brain consumes at least $20 \%$ of the energy produced by mitochondria (Belanger, Allaman, \& Magistretti, 2011). However, defected energy metabolism of mitochondria is one of the prerequisites for psycho-neurological diseases (Gardner \& Boles, 2005; Kaplan et al., 2015). Various studies have shown that the use of both single-nutrients and multi-nutrients formulas in the treatment of psycho-neurological diseases can lead to an overall positive result (Kaplan et al., 2015). In general, approximately 40-50 nutrients (vitamins, minerals, amino acids and unsaturated fatty acids) are identified as essential in human diet and important to ingest (Ames, Elson-Schwab, \& Silver, 2002).

It is known that there is a strong correlation between diet and mental health (Hidaka, 2012) and malnutrition can contribute to the development of various psycho-neurological diseases (Kimball, Mirhoddeini, \& Rucklidge, 2018). N-3 fatty acid deficiency is observed in patients with psychoneurological diseases; therefore, fish oil containing EPA and DHA is used in the treatment of depression, bipolar disorder, and schizophrenia (Lakhan, \& Vieira, 2008). Studies analysing the role of n-3 fatty acids in the diet have provided conclusive evidence that they are important for the development of a child, as well as for cardiovascular diseases, cancer, and psycho-neurological diseases (Riediger et al., 2009). However, fatty acid composition plays an important role in ensuring mental well-being. A study

\footnotetext{
* Corresponding Author's email:

Ilze.Beitane@1lu.lv
} 
conducted by Wolf et al. (2009) found that increased intake of n-9 fatty acids reduces the risk of severely depressed mood in women, while increased intake of n-6 fatty acids increases the risk of severely depressed mood in men. In contrast, a study conducted by Daley et al. (2014) found that increased intake of $\alpha$-linolenic acid reduces the likelihood of depressive symptoms, while increased n-6 fatty acids and decreased n-9 fatty acids reduce the risk of anxiety. Another study found that long-term use of polyunsaturated fatty acids could alleviate symptoms of depression (Yary, \&Aazami, 2011).

Studies have shown that fatty acid profile plays an important role in the treatment of psycho-neurological diseases; therefore, the aim of the current study was to evaluate fatty acid profile in the diet of patients in three Latvian psycho-neurological hospitals.

\section{Materials and Methods}

The study was conducted in the spring of 2019 in which three Latvian psycho-neurological hospitals participated. Hospitals provide 24-hour patient care, so each hospital submitted a detailed one-week menu. The menus included information on products, their quantity, mealtimes, nutritional (protein, fat and carbohydrates) and energy value. Energy value and nutrient rations for the basic diet for patients in medical treatment institutions are determined by Cabinet of Ministers Regulation No 172 of the Republic of Latvia, where the daily energy value for adults is $2250 \mathrm{kcal}( \pm 10 \%)$ and the fat concentration is from $47 \mathrm{~g}$ to $93 \mathrm{~g}$.

The psycho-neurological hospital menus mainly included the following product groups: cereals and bread, meat and meat products, milk and milk products, vegetables, fats and sweets. The amount of fruits and fish and fish products included in the menus was insufficient. Patients were not provided with 2 servings of fruit per day, and fish and fish products were not included in the menu at least twice a week. The one-week menu of two psycho-neurological hospitals included fish once a week, while one-week menu of hospital No. 2 did not include it at all.

A total of 21 menus were analysed in the study. The information on the menus was processed using the Fineli program (https://fineli.fi/fineli/fi/index) on the website of the National Food Composition Database in Finland. The following quantities were determined for each menu: total polyunsaturated fatty acids (PUFA), n-3 polyunsaturated fatty acids (n-3 PUFA), n-6 polyunsaturated fatty acids (n-6 PUFA), mono-unsaturated (MUFA) and saturated fatty acids (SFA), trans-fatty acids (TFA), eicosapentaenoic acid (EPA), docosahexaenoic acid (DHA), linoleic acid (LA) and $\alpha$-linolenic acid (ALA). The data obtained were applied to the total daily intake, assuming that patients ate all food served during the day.

Statistical analyses have been carried out using MS Excel and IBM SPSS Statistics 22. Mean + standard deviation (SD), minimum (Min) and maximum (Max) values were used as descriptive statistical methods.

\section{Results and Discussion}

In the analysed psycho-neurological hospital menus, the average fat concentration ranged between $74.8 \mathrm{~g}$ and $96.1 \mathrm{~g}$, where the fat concentration was closer to the upper limit according to Cabinet of Ministers Regulation No 172. However, the recommendation on SFA did not follow the menu of the psycho-neurological hospital. According to the recommendations of the Ministry of Health (2017) for the nutritional intake of the Latvian population, the concentration of SFA does not exceed $10 \%$ of the total amount of energy. Similar recommendations have been developed by the Agency for Clinical Innovation (2013), stating that the concentration of SFA and trans-fatty acids should not exceed $10 \%$ of the total amount of daily energy. This means that the concentration of SFA must not exceed $31 \mathrm{~g}$. The calculations showed that the average concentration of SFA in different psycho-neurological hospitals menus ranges from $37.5 \mathrm{~g}$ to $47.7 \mathrm{~g}$ (Table 1 ), which is more than recommended. The concentration of SFA on the menu was made up of butter, which was included in the menu every day in all psycho-neurological hospitals, a total of $20 \mathrm{~g}$ a day, which in turn is $10.6 \mathrm{~g}$ of SFA. While the average concentration of unsaturated fatty acids (sum of PUFA and MUFA) varied between $35.9 \mathrm{~g}$ and $47 \mathrm{~g}$, which means that the ratio of saturated to unsaturated fatty acids was 1 to 1 . Consequently, adjustments should be made to the menus of the psycho-neurological hospital in order to achieve the desired result. The quantity of butter in the daily diet must be assessed first. The results of a longitudinal study in the UK confirmed that a diet high in butter may be a risk factor for cognitive impairment in the elderly (Granic et al., 2016). By halving the amount of butter, significant changes in patient diet can be achieved.

Dietary intake of low trans-fatty acids plays an important role in maintaining health, the WHO recommends (Draft guidelines on saturated fatty acid and trans-fatty acid intake for adults and children) that the daily intake of trans-fatty acids should be less than $1 \%$ of total daily energy intake. This means that in this case the trans-fatty acids concentration must not exceed $2.5 \mathrm{~g}$ per day. This condition was observed in all menus in all psycho-neurological hospitals, except for one day in hospital No. 2, where the trans-fatty acid concentration was $3.0 \mathrm{~g}$. It was not related to the 
inclusion of one particular product on the menu, but to the amount of different products.

The ratio of n- $6 / n-3$ fatty acids in the meals of hospital No. 1 was 7.2/1, in hospital No. 2 was 3.8/1, and in hospital No. 3 was $7.7 / 1$. For comparison the recommended n-6 / n-3 fatty acids ratio should be 3/1 1/1 (Kim et al., 2007). The obtained ratio could be assessed as positive because a low n- 6 / n-3 fatty acids ration reduces the risk of many diseases, including depression. Further studies have shown that the ratio of n-6/n-3 fatty acids in the western diet is $15 / 1$ 16.7/1 (Simopoulos, 2006), but in the USA in 2016 it is reported as 25/1 (Husted, \& Bouzinova, 2016). N-3 fatty acids play an important role in provision and prevention of mental health, studies have shown that people with psycho-neurological diseases have low levels of n-3 fatty acids, including EPA and DHA in cell tissue (Su et al., 2003; Peet, \& Stokes, 2005; Su et $a l ., 2015)$, and it is therefore important that these fatty acids are included in sufficient amounts in the diet of psychiatric patients. For individuals with psychoneurological diseases, the n-3 PUFA in the amount of $9.6 \mathrm{~g}$ is considered safe and effective, compared to $1-2 \mathrm{~g}$ /day for a healthy individual (Lakhan, \& Vieira, 2008). The current study showed that the n-3 PUFA concentration was consistent with the recommendations of a healthy individual, but it did not meet the needs of patients in a psycho-neurological hospital. Studies have shown that the addition of n-3 PUFA has a positive effect on the treatment of depression and schizophrenia in patients who have no response to standard therapy (Peet, \& Stokes). Another study showed that increased ALA intake was associated with lower depression symptoms among women (Daley et al., 2014). Studies showed that diet can promote the treatment of psychiatric patients, which means psycho-neurological hospitals should pay more attention to patient's diet.

When assessing the concentration of EPA and DHA in the hospital menus and compared to EFSA recommendations (EFSA, 2017), that the concentration of EPA and DHA should have a daily intake of 250 to $500 \mathrm{mg}$ to reduce the risk of mortality from coronary heart disease, none of the hospital menus reached even the lowest value, as the total concentration of EPA and DHA on the hospital menus ranged from 0.03 to 0.13 g (30-130 mg). The Agency for Clinical Innovation (2013) guidelines for mental health patients state that the diet should provide an average of $430 \mathrm{mg}$ EPA and DHA per day. The low concentration of EPA and DHA could be explained by the products selected on the hospital menus, as it is known, EPA and DHA are found mainly in fatty fish and fish oil, while fish was included in hospital menus only once a week. In addition, hospital No. 2 fish was not included in any of the weekly menus, which explains the lower EPA and DHA concentration among all hospital menus. Similar conclusions could be drawn on the concentration of LA and ALA in hospital menus. The assessment of LA and ALA concentration of hospital menus is close to optimal, as the Food and Nutrition Board of the US Medical Institute (2002) has published adequate intake levels for LA and ALA - $12.0 \mathrm{~g}$ and $1.1 \mathrm{~g}$ per day for women and $17.0 \mathrm{~g}$ and $1.6 \mathrm{~g}$ per day for men, respectively.

Despite a variety of menus in different psychoneurological hospitals, the choice of products was similar, so the profile of fatty acids on the menu (Table 1)

Fatty acid profile in patients' diets classified in psycho-neurological hospitals

Table 1

\begin{tabular}{|l|c|c|c|c|c|c|c|c|c|c|c|c|}
\hline \multirow{2}{*}{ Fatty acids } & \multicolumn{4}{|c|}{ Hospital No. 1 } & \multicolumn{4}{c|}{ Hospital No. 2 } & \multicolumn{3}{c|}{ Hospital No. 3 } \\
\cline { 2 - 13 } & Mean & SD & Min & Max & Mean & SD & Min & Max & Mean & SD & Min & Max \\
\hline SFA, g & 41.7 & 7.8 & 34.2 & 57.2 & 37.5 & 6.7 & 28.5 & 48.1 & 47.7 & 5.0 & 37.9 & 52.7 \\
\hline TFA, g & 1.4 & 0.3 & 1.0 & 2.0 & 1.4 & 0.7 & 1.0 & 3.0 & 1.4 & 0.2 & 1.2 & 1.7 \\
\hline MUFA, g & 25.3 & 3.9 & 20.4 & 30.7 & 23.9 & 5.1 & 16.5 & 29.7 & 31.5 & 5.5 & 24.4 & 39.6 \\
\hline PUFA, g & 15.3 & 2.6 & 12.6 & 19.0 & 12.0 & 3.5 & 6.1 & 14.1 & 15.5 & 3.4 & 8.7 & 20.1 \\
\hline $\begin{array}{l}\text { n-3 PUFA, } \\
\text { g }\end{array}$ & 1.8 & 0.3 & 1.3 & 2.1 & 2.2 & 0.5 & 1.0 & 2.5 & 1.7 & 0.4 & 1.1 & 2.1 \\
\hline $\begin{array}{l}\text { n-6 PUFA, } \\
\text { g }\end{array}$ & 13.0 & 2.4 & 10.1 & 16.3 & 8.4 & 3.1 & 4.6 & 12.4 & 13.1 & 3.2 & 7.1 & 17.5 \\
\hline EPA, g & 0.02 & 0.01 & 0.004 & 0.04 & 0.01 & 0.01 & 0.0 & 0.04 & 0.04 & 0.03 & 0.02 & 0.11 \\
\hline DHA, g & 0.06 & 0.03 & 0.02 & 0.12 & 0.02 & 0.03 & 0.003 & 0.06 & 0.09 & 0.06 & 0.02 & 0.11 \\
\hline LA, g & 12.7 & 2.4 & 9.7 & 15.8 & 8.2 & 3.0 & 4.7 & 12.2 & 12.8 & 3.2 & 9.7 & 15.8 \\
\hline ALA, g & 1.7 & 0.3 & 1.1 & 2.0 & 1.2 & 0.2 & 0.9 & 1.3 & 1.5 & 0.4 & 1.1 & 2.0 \\
\hline
\end{tabular}


did not differ significantly $(p>0.05)$ among psychoneurological hospitals. The profile of fatty acids depend on the product chosen, as indicated by the minimum and maximum values on the menu, for example, the inclusion of fish in the menu increased the concentration of MUFA and PUFA. In hospital No.1, herring was included in one of the menus, while in hospital No. 3 was fish soup which allowed to reach the maximum concentration of MUFA (respectively $30.7 \mathrm{~g}$ and 39.6 g) and PUFA (respectively $19.0 \mathrm{~g}$ and $20.1 \mathrm{~g}$ ) per day for each menu. However, the choice of other products on that day was also important in order to reach the maximum daily intake of unsaturated fatty acids. None of the weekly menus included fish or fish products in hospital No. 2, which explains the lowest maximum value among psycho-neurological hospital menus.

The minimum and maximum values of the current study showed that fatty acid profile in the psychoneurological hospital menus was not analysed, it differed significantly from day to day and, for example, SFA difference in hospital No. 1 between the various days was $23 \mathrm{~g}$ or EPA - ten times. This leads to the conclusion that the impact of diet on the treatment of psycho-neurological diseases in Latvian psycho-neurological hospitals has not been sufficiently assessed.

\section{Conclusions}

Patients' diet in Latvian psycho-neurological hospitals is formed in accordance with Cabinet of Ministers Regulation that determines the total fat concentration per day, but does not provide any more detailed recommendations for fatty acids. When evaluating fatty acid profile, it should be concluded that recommendations for the diet of psychoneurological hospital patients would be required. In general, it would be necessary to increase n-3 PUFA, reduce SFA concentration for patients' diets.

\section{References}

Agency for Clinical Innovation. (2013). Nutrition standards for consumers of impatient mental health services in NSW. Retrieved October 20, 2020, from: https:/www.aci.health.nsw.gov. $\mathrm{au} / \mathrm{data} / \mathrm{assets} / \mathrm{pdf}$ file/0013/201091/ACINutrition-Mental-Health-Inpatients-web-final. pdf

Ames, B.N., Elson-Schwab, I., \& Silver, E. (2002). High-dose vitamin therapy stimulates variant enzymes with decreased coenzyme binding affinity (increased $\mathrm{K}_{\mathrm{m}}$ ); Relevance to genetic disease and polymorphisms. Am. J. Clin. Nutr. 75, 616-658. DOI: 10.1093/ajen/75.4.616.

Belanger, M., Allaman, I., \& Magistretti, P.J. (2011). Brain energy metabolism: Focus on astrocyte- neuron metabolic cooperation. Cell Metab. 14, 724-738. DOI: 10.1016/j.cmet.2011.08.016.

Daley, C., Patterson, A., Sibbritt, D., \&MacDonaldWicks, L. (2014). Unsaturated fat intakes and mental health outcomes in young women from Australian longitudinal study on women's health. Public Health Nutr. 18(3), 546-553. DOI: 10.1017/S1368980014000561.

European Food Safety Authority (EFSA) (2017, December). Dietary Reference Values for nutrients. Summary report. Retrieved August 27, 2020, from: https://efsa.onlinelibrary.wiley.com/ doi/10.2903/sp.efsa.2017.e15121

Gardner, A., \& Boles, R.G. (2005). Is a "mitochondrial psychiatry" in the future? A Review. Curr. Psychiat. Rev. 1, 255-271. DOI: 10.2174/157340005774575064.

Granic, A., Davies, K., Adamson, A., Kirkwood, T., Hill, T.R., Siervo, M., Mathers, J.C., \& Jagger, C. (2016, January). Dietary patterns high in red meat, potato, gravy, and butter are associated with poor cognitive functioning but not with rate of cognitive decline in very old adults. The Journal of Nutrition, 265-274. DOI: 10.3945/ jn.115.216952

Hidaka, B.H. (2012). Depression as a disease of modernity: explanations for increasing prevalence. J.Affect. Disord. 140(3), 205-214. DOI: $10.1016 /$ j.jad.2011.12.036.

Husted, K.S., \&Bouzinova, E.V. (2016). The importance of n-6/n-3 fatty acids ratio in the major depressive disorder. Medicina 52, 139147. DOI: 10.1016/j.medici.2016.05.003

Institute of Medicine. (2002). Dietary Reference Intakes for Energy, Carbohydrate, Fiber, Fat, Fatty Acids, Cholesterol, Protein, and Amino Acids. Washington, D. C.: National Academies Press.

Kaplan, B.J., Rucklidge, J.J., Romijn, A., \& McLeod, K. (2015). The emerging field of nutritional mental health: Inflammation, the microbiome, oxidative stress, and mitochondrial function. Clinic. Psychol. Sci. 3, 964-980. DOI: 10.1177/2167702614555413.

Kim, S.C, Adesogan, A.T., Bading, L., \& Staples, C.R. (2007). Effects of dietary n-6: n-3 fatty acid ratio on feed intake, digestibility, and fatty acid profiles of the ruminal contents, liver, and muscle of growing lambs. J.Anim.Sci. 85(3), 706-716. DOI: $10.2527 /$ jas.2006-289

Kimball, S.M., Mirhosseini, N., \& Rucklidge, J. (2018). Database analysis of depression and anxiety in a community sample - response to a micronutrient intervention. [Electronic version]. Nutrients 10(152). DOI: 10.3390/nu10020152. 
Lakhan, S.E., \& Vieira, K.F. (2008, January). Nutritional therapies for mental disorders. [Electronic version]. Nutr. J. 7(2), 1-8. DOI: 10.1186/1475-2891-7-2.

Ministry of Health. (2017, November). Recommended energy and nutrient intakes for the population of Latvia. Retrieved August 18, 2020, from http:// www.vm.gov.lv/images/userfiles/Tava\%20 veseliba/Ieteicam $\% \mathrm{C} 4 \% 81$ s_ener $\% \mathrm{C} 4 \% \mathrm{~A} 3 \mathrm{ijas}$ un_uzturvielu_devas.pdf

Peet, M., \& Stokes, C. (2005). Omega-3 fatty acids in the treatment of psychiatric disorders. Drugs 65(8), 1051-1059. Retrieved August 28, 2020, from http://www.uppitysciencechick.com/peet omega3review.pdf

Republic of Latvia. Cabinet Regulation No. 172 (2012, March). Regulations Regarding Nutritional Norms for Educatees of Educational Institutions, Clients of Social Care and Social Rehabilitation Institutions and Patients of Medical Treatment Institutions. Retrieved August 18, 2020, from https://likumi.lv/ta/en/en/id/245300-regulationsregarding-nutritional-norms-for-educateesof-educational-institutions-clients-of-socialcare-and-social-rehabilitation-institutions-andpatients-of-medical-treatment-institutions

Riediger, N.D., Othman, R.A., Suh, M., \& Moghadasian, M.H. (2009). A systematic review of the roles of n-3 fatty acids in health and disease. J. Am. Diet. Assoc. 109, 668-679. DOI: 10.1016/j.jada.2008.12.022.

Simopoulos, A.P. (2006). Evolutionary aspects of diet, the omega-6/0mega-3 ratio and genetic variation: nutritional implications for chronic diseases. Biomedicine \& Pharmacotherapy 60, 502-507. DOI: https://doi.org/10.1016/j. biopha.2006.07.080.

Su, K.P., Huang, S.Y., Chiu, C.C., \& Shen, W.W. (2003). Omega-3 fatty acids in major depressive disorder. A preliminary doubleblind, placebo-controlled trial. European NeuroPsychopharmacology 13, 267-271. DOI: 10.1016 / S0924-977X(03)00032-4.

Su, K.P., Matsuoka, Y., \& Pae, C.U. (2015). Omega-3 polyunsaturated fatty acids in prevention of mood and anxiety disorders. Clinical Psychopharmacology and Neuroscience 13(2), 129-137. DOI: 10.9758/cpn.2015.13.2.129.

Wolf, A.R., Ogbonna, E.M., Lim, S., Li, Y., \& Zhang, J. (2009). Dietary linoleic and oleic fatty acids in relation to severe depressed mood: 10 years follow-up of a national cohort. Prog. NeuroPsychopharmacol. Biol. Psychiatry 33, 972-977. DOI: 10.1016/j.pnpbp.2009.05.002.

World Health Organization. Draft guidelines on saturated fatty acid and trans-fatty acid intake for adults and children. Retrieved August 18, 2020, from https://extranet. who.int/dataform/upload/surveys/666752/ files/Draft $\% 20$ WHO $\% 20$ SFA-TFA $\% 20$ guidelines_04052018\%20 Public\%20 Consultation(1).pdf

Yary, T., \& Aazami, S. (2011). The association between polyunsaturated fatty acids and depression among Iranian postgraduate students in Malaysia. [Electronic version]. Lipids Health Dis. 10(151). DOI: 10.1186/1476-511X-10-151. 